\title{
Potential Use of Copper Oxide Nanoparticles from Solanum trilobatum Against Pathogenic Bacteria
}

\author{
M. STELLA BHARATHY*, G. DAYANA JEYALEELA, \\ J. ROSALINE VIMALA, A. AGILA and M. HEMADEVI \\ Department of Chemistry, Holy Cross College (Autonomous), Affiliated to \\ Bharathidasan University, Tiruchirappalli-620 002, Tamil Nadu, India. \\ *Corresponding author E-mail: stelladharshu@gmail.com, \\ http://dx.doi.org/10.13005/ojc/370429
}

(Received: July 07, 2021; Accepted: August 10, 2021)

ABSTRACT

\begin{abstract}
Recently, the biosynthesis of metal oxide nanoparticles using plant extract gained great attention compared to other methods. In this work, $\mathrm{CuO}$ nanomaterial was synthesized by using the leaf extract of Solanum trilobatum. Synthesized copper oxide nanoparticles were characterized by UV, FT-IR, XRD, SEM, and EDX to determine the functional group, crystalline size, shape, and elemental composition of the synthesized nanoparticles. The X-ray diffraction and SEM results confirmed that the synthesized CuO NPs were crystalline in nature and the average size was found to be $38.34 \mathrm{~nm}$. The spherical shape of CuO NPs was reported in the green approach, but firsttime pentagons, cubes, and elongated forms of CuO NPs are found in this work. The EDX studies showed that the Solanum trilobatum mediated CuO NPs contain $53.57 \%$ of copper and $46.43 \%$ of oxygen. Synthesized CuO NPs were tested against the five pathogenic bacteria and they showed a very good zone of inhibition compared with copper sulfate and plant extract. Especially against Escherichia coli, Solanum trilobatum mediated CuO NPs performed well inhibitory effect.
\end{abstract}

Keywords: Biosynthesis, Solanum trilobatum, Characterization, and Pathogenic bacteria.

\section{INTRODUCTION}

Bacterial diseases present unfavorable impacts on human wellbeing. Bacteria can affect any part(s) of the human body ${ }^{1}$. Bacterial diseases are the primary driver of persistent contaminations and mortality. An infectious disease caused by bacteria getting into the human body produces chemicals called a toxin, which can damage or destroy the tissues. Bacterial infections include urinary tract infections (cystitis), respiratory system/tract infections (laryngitis, pharyngitis, tonsillitis), gastrointestinal infections (inflammation in stomach, intestines), bone and joint infections (osteomyelitis, septic arthritis), soft tissue infections (pyoderma, necrotizing), skin infections (cellulitis, erysipelas), wound infections, burn infections, bloodstream infections (toxemia), and other clinical infections (neonatal meningitis, pneumonia) ${ }^{2}$. In this work five main infection-causing bacteria are used: Escherichia coli, Enterococcus aerogenes, Pseudomonas aeruginosa, Staphylococcus aureus, and Proteus vulgaris which causes intestinal infections,

This is an Open Access article licensed under a Creative Commons license: Attribution 4.0 International (CC- BY). Published by Oriental Scientific Publishing Company @ 2018 
respiratory tract infections, bone and joint infections, skin infections, and nosocomial wound infections respectively. All the above-mentioned bacteria in common cause urinary tract infection disease ${ }^{3}$.

Nanoscience/nanotechnology has been applied extensively in pharmacological activities (drug delivery, biological applications) to develop and improve the therapeutic outcomes of several diseases. Nowadays nanoparticles were increasingly used as an alternative antibiotic against various bacteria and bacterial infectious diseases ${ }^{4-6}$. Copper oxide nanoparticles are utilized to prevent infection, control bacterial infections (an antibacterial vaccine), treat infectious disease (as an antibiotic), promote wound healing, and generate microbial diagnostics (in bacterial detection systems $)^{7-9}$. Other than antibiotic effects CuO NPs have reported numerous therapeutic outcomes such that, antioxidant effects, immunomodulatory, sunscreen, and anticancer. Copper oxide nanoparticles assume a significant part in the field of medication. Solanum trilobatum is said to possess good antimicrobial activity ${ }^{10,11}$. The present work aimed to explore the potential of Solanum trilobatum as a biosource for copper oxide nanoparticles synthesis. Furthermore, the antibacterial activity of copper oxide nanoparticles against Escherichia coli, Enterococcus aerogenes, Pseudomonas aeruginosa, Staphylococcus aureus, and Proteus vulgaris was analyzed by the disc diffusion method.

\section{EXPERIMENTAL METHODS}

\section{Materials and reagents}

Copper(II) sulfate pentahydrate $\left(\mathrm{CuSO}_{4} \cdot 5 \mathrm{H}_{2} \mathrm{O}\right)$ and ethanol $\left(\mathrm{C}_{2} \mathrm{H}_{5} \mathrm{OH}\right)$ were of analytical grades purchased from Merck. Preparation of the precursor copper solution is prepared by using the double-distilled (D.D) water.

\section{Preparation of Solanum trilobatum extract}

The fresh leaves of Solanum trilobatum were washed properly and shade dried. $500 \mathrm{~g}$ of powdered Solanum trilobatum leaves were taken in a $500 \mathrm{~mL}$ beaker and added ethanol solvent, mixed well, and kept aside for at least 3 to 5 days. After the complete extraction, the extract was filtered and the filtrate was stored in a refrigerator for future experimental work.

\section{Preparation and Characterization of Solanum trilobatum Mediated CuONPs}

$50 \mathrm{~mL}$ of $0.1 \mathrm{M}$ copper sulfate solution were taken in $250 \mathrm{~mL}$ beaker and placed on a magnetic stirrer at $60^{\circ} \mathrm{C}$. $10 \mathrm{~mL}$ of Solanum trilobatum extract was slowly added at every 30 min interval. After completion of the reaction, the reaction mixture was kept overnight at room temperature. Copper oxide nanoparticles were obtained by centrifuging at $6,000 \mathrm{rpm}$ for 15 minutes. The precipitate was dried in an oven for the complete conversion of copper hydroxide into oxide. Finally, the purified copper oxide Nanoparticles (CuONPs) were further taken for characterization and microbial activity.

UV-spectrophotometer (Perkin Elmer make UV-Visible spectrometer and lambda 35 models) was used to characterize the optical properties of the synthesized nanoparticles. The Fourier transform infrared spectroscopy (Shimadzu) was analyzed to detect the functional and chemical group (range of $4000-400 \mathrm{~cm}^{-1}$ ). X-ray diffraction (Shimadzu) studies were used to find the crystallographic structure of a material. The scanning electron microscopy (JEOL JSM-6480 LV SEM) was used to determine the morphology of the nanoparticles. Energy Dispersive $\mathrm{X}$-ray Analysis (Bruker) was carried out to detect the elemental composition.

\section{Antibacterial activity of Solanum trilobatum Mediated CuONPs}

Antibacterial potential of synthesized CuONPs was investigated against the infectioncausing bacteria such as Enterococcus aerogenes, Staphylococcus aureus, Escherichia coli, Pseudomonas aeruginosa, and Proteus vulgaris by the disc diffusion method. Positive control was prepared using $10 \mu \mathrm{l}$ of Amoxicillin as a standard antibiotic disc. The nutrient agar medium was prepared and sterilized by autoclaving at $121^{\circ} \mathrm{C} 15$ lbs pressure for $15 \mathrm{~min}$ then aseptically poured the medium into the sterile Petri plates and allowed to solidify the Bacterial broth culture was swabbed on each Petri plate using sterile buds. The extract, precursor, and nanoparticles were added to each well aseptically. This procedure was repeated for each Petri plate then the Petri plates were incubated at $37^{\circ} \mathrm{C}$ for 24 hours. After incubation, the plates were observed for the zone of inhibition ${ }^{12}$. 


\section{RESULTS AND DISCUSSION}

\section{Characterization of Solanum trilobatum Mediated CuONPs \\ UV-Visible result of CuONPs and Solanum trilobatum extract}

Preliminarily the formation of copper oxide nanoparticles was confirmed by the color changes in the reaction mixture, before and after adding the leaf extract. The color change from blue to dark green indicated the production of copper oxide nanoparticles. UV-spectra of Solanum trilobatum extracts and qualitative analysis reveal the flavonoids aromatics (nucleus) are mostly present in it which is shifted to $419 \mathrm{~nm}$ in the UV-spectrum of synthesized CuONPs. Flavonoids biomolecules in the extract play a key role in the conversion of $\mathrm{Cu}^{2+}$ to $\mathrm{Cu}^{0}$ (from Figure $\left.1 \& 2\right)^{13,14}$.

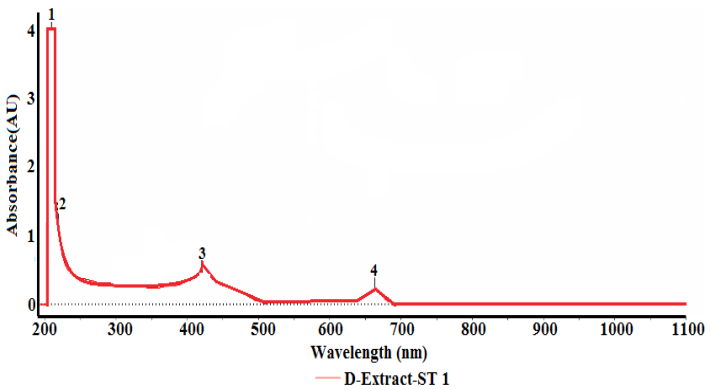

Fig. 1. UV-Visible spectrum of Solanum trilobatum extract

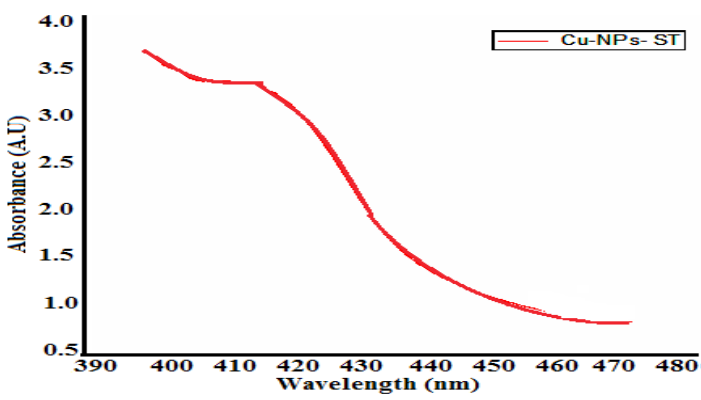

Fig. 2. UV-Visible spectrum of Solanum trilobatum mediated CuONPs

FT-IR result of CuONPs and Solanum trilobatum extract

FT-IR spectra and functional group involved in CuONPs synthesis illustrated peaks in the range of $400-4000 \mathrm{~cm}^{-1}$ (Fig. 3,4 and Table 1,2). The Solanum trilobatum extract shows a broad peak at $3396 \mathrm{~cm}^{-1}$ which indicates the presence of $\mathrm{O}-\mathrm{H}$ groups and after the synthesis of Copper oxide nanoparticles, there is a shift in the broad peak to the $3434 \mathrm{~cm}^{-1}$, which indicates that some polyhydroxy compounds, such as terpenoids, polyester or flavonoids or phenolic compounds involved the reducing process ${ }^{15,16}$.

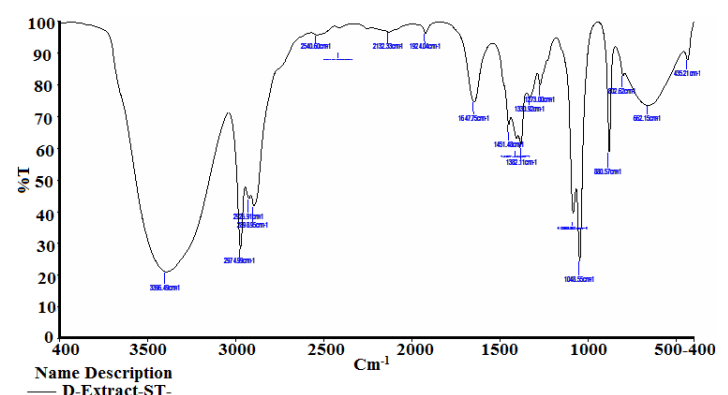

Fig. 3. FT-IR spectrum of Solanum trilobatum extract

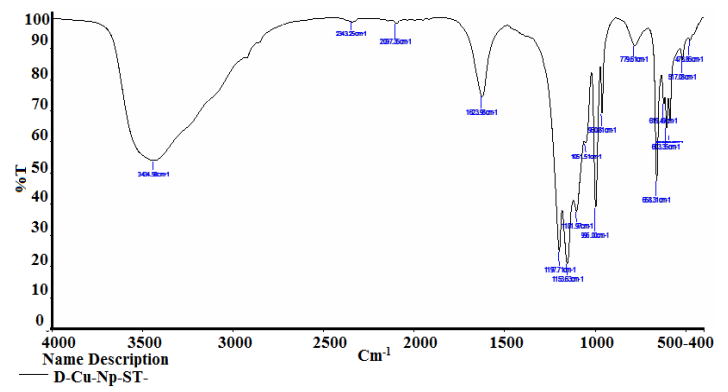

Fig. 4. FT-IR spectrum of Solanum trilobatum mediated CuONPs

Table 1: FT-IR spectral peaks of plant extract

\begin{tabular}{|c|c|c|}
\hline S.No & Absorption peak $\left(\mathrm{cm}^{-1}\right)$ & Functional groups \\
\hline 1 & 3396 & $\begin{array}{l}\text { OH stretching of carbohydrates, } \\
\text { proteins, and polyphenols }\end{array}$ \\
\hline 2 & 2974 & $\mathrm{C}-\mathrm{H}$ stretching of proteins \\
\hline 3 & 1647 & $\mathrm{C}=\mathrm{C}$ stretching of cellulose \\
\hline 4 & 1048 & C-N stretching of cellulose \\
\hline 5 & 802 & $\mathrm{C}-\mathrm{H}$ stretching of aromatic rings \\
\hline 6 & 662 & $\mathrm{C}-\mathrm{Cl}$ stretching of alkyl halides \\
\hline 7 & 435 & C-I stretching of alkyl halides \\
\hline
\end{tabular}

Table 2: FT-IR spectral peaks of synthesized CuONPs

\begin{tabular}{ccl} 
S.No & Absorption peak $\left(\mathrm{cm}^{-1}\right)$ & Functional groups \\
\hline 1 & 3434 & $\begin{array}{l}\text { OH stretching of carbohydrates, } \\
\text { proteins, and polyphenols }\end{array}$ \\
2 & 2097 & $\begin{array}{l}\text { C-H stretching of proteins } \\
3\end{array}$ \\
4 & 1623 & C=C stretch of lignin \\
5 & 1153 & C-O stretching of cellulose \\
6 & 1051 & C-O stretching of cellulose \\
7 & 658 & C-Cl stretching of alkyl halides \\
\hline
\end{tabular}

\section{XRD result of CuONPs}

The formation of $\mathrm{CuO}$ nanoparticles was confirmed by XRD analysis. The significant $2 \theta$ values appeared at $34.78^{\circ}, 36.20^{\circ}, 39.80^{\circ}, 44.78^{\circ}$, $54.82^{\circ}, 57.77^{\circ}$, and $75.52^{\circ}$ which corresponds to (110), (002), (111), (202), (020), (202), and (004) 
planes respectively. Formed CuONPs were found to be monoclinic crystallite and are very close to those in the JCPDS File no. 5-0661 (Fig. 5). The result is similar to the reported data ${ }^{17,18}$. Peaks between $20^{\circ}$ to $30^{\circ}$ were due to impurity peaks i.e. plant compounds interference. The average crystallite size of the observed CuONPs calculated using the Debye Scherer formula was about $38.34 \mathrm{~nm}$.

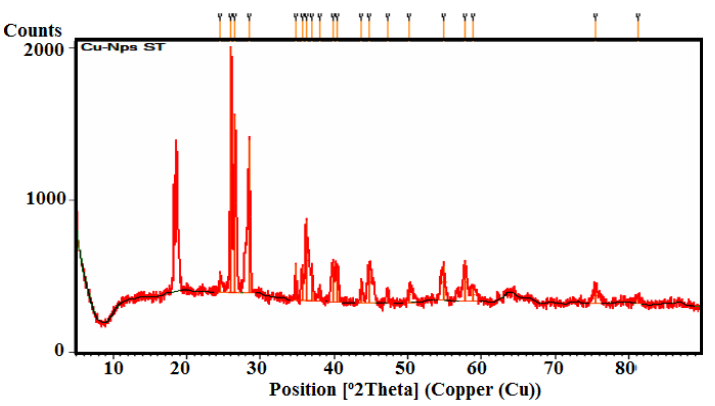

Fig. 5. XRD spectrum of Solanum trilobatum mediated CuONPs

\section{SEM images of CuONPs}

SEM micrographs (Fig. 6) of the CuO NPs obtained by the biosynthesis method revealed that the copper oxide particles were pentagons, cubes, and elongated with different sizes. They were also seen to be present in small aggregated/ clustered forms ${ }^{19}$. Usually, nanoparticle shape was depending on reducing agent concentrations. The reducing agent which has lower reducing power commonly forms the spherical shapes of CuONPs and the strong reducing agent forms the different shapes of nanoparticles.

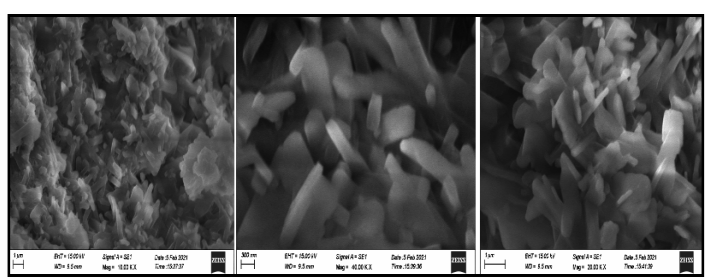

Fig. 6. SEM micrographs of Solanum trilobatum mediated CuONPs

\section{EDX of CuONPs}

Energy Dispersive Spectroscopy (EDX) was used to find the elemental composition in the formed CuONPs. EDX of copper oxide nanoparticles revealed the presence of pure copper at $53.57 \%$ and oxygen at $46.43 \%$ as shown in Fig. 7 . Another prominent peak seen may be due to the presence of minerals in the extract of Solanum trilobatum ${ }^{20}$.

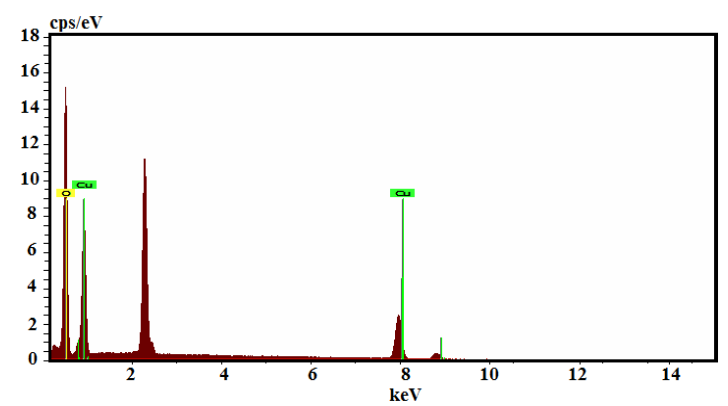

Fig. 7. EDX image of Solanum trilobatum mediated CuONPs Anti-bacterial results of Solanum trilobatum Mediated CuONPs

Antibacterial activity of synthesized copper oxide nanoparticles was investigated against five different pathogenic bacteria Escherichia coli, Enterococcus aerogenes, Pseudomonas aeruginosa, Staphylococcus aureus, and Proteus vulgaris to amoxicillin. Synthesized CuONPs showed a very good zone of inhibition compared with the precursor and plant extract. Pseudomonas aeruginosa and Proteus vulgaris, don't show any inhibitory effect but copper nanoparticles revealed a noticeable zone of inhibitions. A maximum zone of inhibition was observed against the Gram-negative Escherichia coli21. (Table 3). Copper oxide nanoparticles have potential antimicrobial action given their enormous surface region, which clears the route for great contact with microorganisms ${ }^{22}$. The correct mechanism behind the destruction is not known, which has to be studied further in detail. As per the literature, Gramnegative bacteria show good inhibition than Grampositive bacteria ${ }^{23}$. The results indicate that the synthesized copper nanoparticles show effective antimicrobial activity against pathogenic bacteria.

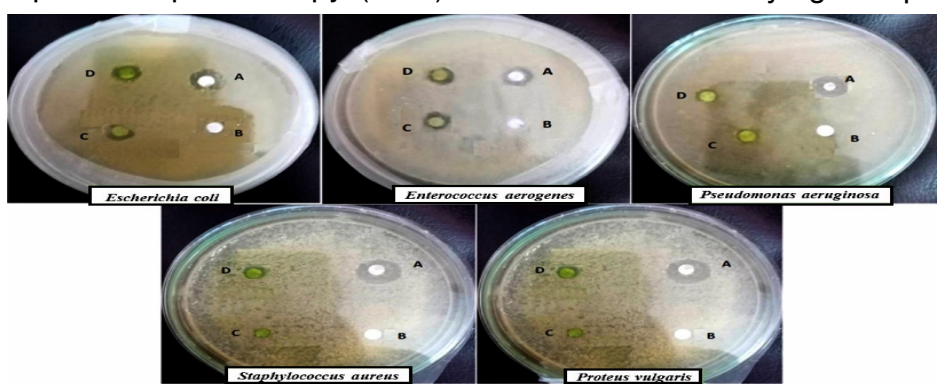

Fig. 8. Images of Solanum trilobatum mediated CuONPs, Solanum trilobatum extract, and copper solution against five infection-causing bacteria 
Table 3: Antibacterial activity of Solanum trilobatum extract, Copper Sulphate, CuO NPs, and standard amoxicillin on pathogenic bacteria

\begin{tabular}{lcccc}
\hline Microorganisms & \multicolumn{2}{c}{ Zone of Inhibition (mm) $(10 \mu \mathrm{l})$} \\
& $\mathrm{A}($ Amoxicillin) & $\mathrm{B}$ (Copper sulphate) & $\mathrm{C}$ (Plant extract) & $\mathrm{D}$ (CuONPs) \\
\hline Escherichia coli & $8.0 \pm 0.33$ & 0 & $3.0 \pm 0.13$ & $4.0 \pm 0.16$ \\
Enterococcus aerogenes & $8.0 \pm 0.62$ & 0 & $2.0 \pm 0.20$ & $3.0 \pm 0.20$ \\
Pseudomonas aeruginosa & $7.0 \pm 0.23$ & 0 & 0 & $2.0 \pm 0.13$ \\
Staphylococcus aureus & $80 \pm 0.30$ & 0 & $1.0 \pm 0.25$ & $2.0 \pm 0.17$ \\
Proteus vulgaris & $8.0 \pm 0.66$ & 0 & 0 & $2.0 \pm 0.16$ \\
\hline
\end{tabular}

\section{CONCLUSION}

In this work, the copper nanoparticles were successfully synthesized by green route from Solanum trilobatum leaf extract which acted as a natural reducing agent. The UV-Vis peak at $419 \mathrm{~nm}$ confirmed the synthesis of CuONPs. The FT-IR spectral data confirmed the presence of some polyhydroxy compounds, such as terpenoids, polyester or flavonoids, or phenolic compounds involved in the reduction process of Copper. The particle size using XRD was found to be $38.34 \mathrm{~nm}$. The antibacterial activity against the Gram-negative bacteria i.e. Escherichia coli showed the maximum zone of inhibition. This study proves the biomedical importance of CuONPs on infectious disease-causing bacteria. It may use as good antimicrobial materials and finds application in the field of pharmaceutics.

\section{ACKNOWLEDGEMENT}

The authors would like to thank CECRI Karaikudi for Technical Assistance. The authors thank the Keba Scientific Research Center and Holy Cross College (Autonomous), Trichy for permitting us to do this research work in their laboratory.

\section{Conflict of interest}

All the authors declare that there is no conflict of interest.

\section{REFERENCES}

1. Doron, S.; Gorbach, S.L. Bacterial Infections: Overview. Intl. Ency. Publ. Health., 2008, 273-282.

2. Elisha, I.L.; Botha, F.S.; McGaw, L.J.; Eloff, J.N. The antibacterial activity of extracts of nine plant species with good activity against Escherichia coli against five other bacteria and cytotoxicity of extracts. BMC Complement. Med. Ther., 2017, 133, 1-10.

3. Santhoshkumar, J.; Venkat Kumar, S.; Rajeshkumar, S. Synthesis of zinc oxide nanoparticles using plant leaf extract against urinary tract infection pathogen. ResourceEfficient Technologies., 2017, 3(4), 459-465.

4. Linlin Wang.; Chen Hu.; Longguan Shao. The antimicrobial activity of nanoparticles: present situation and prospects for the future. Int. J. Nanomedicine., 2017, 14(12), 1227-1249.

5. Gopalakrishnan, S.; Philip Kaupa, S.; Lakshmi, Y.S.; Banu, F. Antimicrobial activity of synthesized silver nanoparticles and phytochemical screening of the aqueous extract of Antiaris toxicaria. Indian J. Drugs and Diseases., 2015, 4(1), 1-4.
6. Cioffi, N.; Torsi, L.; Ditaranto, N.; Tantillo, G.; Ghibelli, L.; Sab-batini, L.; Bleve-Zacheo, T.; D’Alessio, M.; Zambonin, P.G.; Tra $\neg$ versa, E. Copper Nanoparticle/Polymer Composites with Antifungal and Bacteriostatic Properties. Chem. Mater., 2005, 17(21), 5255-5262.

7. Das, D.; Nath, B.; Phukon, P.; Dolui, S. Synthesis, and evaluation of antioxidant and antibacterial behavior of $\mathrm{CuO}$ nanoparticles. Coll. Surf. $B$. Biointerfaces., 2012, 1(101), 430-433.

8. Azam, A.; Ahmed, A.S.; Oves, M.; Khan, M.S.; Memic, A. Size-dependent antimicrobial properties of $\mathrm{CuO}$ nanoparticles against Gram-positive and -negative bacterial strains. Int. J. Nanomedicine., 2012, 7, 3527-3535.

9. Rajeshwari Sivaraj.; Pattanathu K.S.M. Rahman.; Rajiv, P.; Hasna Abdul Salam.; Venkatesh, R. Biogenic copper oxide nanoparticles synthesis using Tabernaemontana divaricate leaf extract and its antibacterial activity against urinary tract pathogen. Spectrochim. Acta A Mol. Biomol. Spectrosc., 2014, 10(133), 178-181. 
10. Ramar, M.; Manikandan, B.; Marimuthu, P.N.; Raman, T.; Mahalingam, A.; Subramanian, P.; Karthick, S.; Munusamy, A. Synthesis of silver nanoparticles using Solanum trilobatum fruits extract and its antibacterial, cytotoxic activity against human breast cancer cell line MCF 7. Spectrochim. Acta AMol. Biomol. Spectrosc., 2015, 14O(5), 223-228.

11. Purushothaman Balakrishnan.; ThameemAnsari Musafar Gani.; Sreenath Subrahmanyam.; Kumaran Shanmugam. A perspective on bioactive compounds from Solanum trilobatum. J. Chem. Pharm. Res., 2015, 7(8), 507-512.

12. Rajiv, P.; Rajeshwari, S.; Venkatesh, R. BioFabrication of zinc oxide nanoparticles using leaf extract of Parthenium hysterophorus $L$. and its size-dependent antifungal activity against plant fungal pathogens. Spectrochim. Acta $A$ Mol. Biomol. Spectrosc., 2013, 112, 384-387.

14. Arunachalam, D.K. Kannappan, G. Synthesis of Copper Precursor, Copper and its oxide Nanoparticles by Green Chemical Reduction Method and its Antimicrobial Activity. J. App. Pharm. Sci., 2013, 3(5), 16-21.

15. Deneke Shamebo Menamo.; Delele Worku Ayele.; Mirtachew Tihar Ali. Green synthesis, characterization and antibacterial activity of copper nanoparticles using L-ascorbic acid as a reducing agent. Ethiop. J. Sci. \& Technol., 2017, 10(3), 209-220.

16. Flemming, C.A.; Trevors, J.T.; Copper retention and toxicity in a freshwater sediment. Water Air Soil Pollut., 1989, 4O(1), 419-432.

17. Mehrdad Khatami.; Hossein Heli.; Peyman Mohammadzadeh Jahani.; Hakim Azizi.; Marcos Augusto Lima Nobre. Copper/copper oxide nanoparticles synthesis using Stachys lavandulifolia and its antibacterial activity. IET. Nanobiotechnology., 2017, 11(6), 709-713.

18. Suramwar, N.V.; Thakare, S.R.; Khaty, N.T. Synthesis and catalytic properties of nano $\mathrm{CuO}$ prepared by soft chemical method. Int. J. Nano Dimens., 2012, 3(1), 75-80(2012).

19. Kannaki, K.; Ramesh, P. S.; Geetha, D. Hydrothermal synthesis of CuO Nanostructure and Their Characterizations. Int. J. Sci. Eng. Res., 2012, 3(9), 1-4.

20. Datta, A.; Patra, C.; Bharadwaj, H.; Kaur, S.; Dimri, N.; Khajuria, R. Green Synthesis of Zinc Oxide Nanoparticles Using Parthenium hysterophorus Leaf Extract and Evaluation of their Antibacterial Properties. J. Biotechnol. Biomater., 2017, 7(3), 1000271.

21. Chandan Tamuly.; Indranirekha Saikia.; Moushumi Hazarikaa.; Manash R. Dasb. Reduction of aromatic nitro compounds catalyzed by biogenic $\mathrm{CuO}$ nanoparticles. $R$ S CAdv., 2014, 95(4), 53229.

22. Kim, J.H.; Cho, H.; Ryu, S.E.; Choi, M.U. Effects of Metal lons on the Activity of Protein Tyrosine Phosphatase VHR: Highly Potent and Reversible Oxidative Inactivation by $\mathrm{Cu}^{2+}$ Ion. Arch. Biochem. Biophys., 2000, 382(1), 72-80.

23. Zarrindokht, E.K.; Chehrazi, P. Antibacterial activity of $\mathrm{ZnO}$ nanoparticle on Gram-positive and Gram-negative bacteria. Afr J Microbiol Res., 2011, 5(12), 1368-1373.

24. Ahamed, M.; Alhadlaq, H.A.; Khan, M.A.; Karuppiah, P.; Al-Dhabi, N.A. Synthesis, Characterization, and Antimicrobial Activity of Copper Oxide Nanoparticles. J. Nanomater., 2014, 1-4. 